Esther Hormiga

Universitat de Barcelona (Spain)

Li Xiao

Lancaster University Management School (U.K.)

David Smallbone

Kingston Business School (U.K.)

\title{
Entrepreneurial Dynamics and Institutional Changes
}

\begin{abstract}
Contemporary literature has paid considerable attention to the relationships between formal and informal institutions and early stage firms' behaviours in different institutional settings in recent years. Given a constantly changing business environment in which companies are operating, there is a need to continuously study how they deal with new challenges and how they achieve new goals. It is essential for not only nascent but also experienced entrepreneurs to discover new dynamics in order to stay at a competitive level. This special issue of Journal of Evolutionary Studies in Business aims to explore the role of dynamics that interact with institutional changes in surviving and growing ventures. We present the nine articles with a variety of studied contexts, which shed some light on how companies or organisations keep up with institutional changes at both macro and micro level, by actively transforming business practices and entrepreneurial processes.
\end{abstract}

Keywords: Entrepreneurial dynamics; Institutional changes; Processes; Entrepreneurship

We are delighted to introduce this special issue of Journal of Evolutionary Studies in Business Journal, the purpose of which is to develop a good understanding of the role of entrepreneurial dynamics that interact with institutional changes in surviving and growing new ventures.

Corresponding author: e-mail: ehormiga@ub.edu

Received 11 January 2018 - Accepted 18 January 2018

This is an Open Access article distributed under the terms of the Creative Commons Attribution-Non-Commercial-No Derivatives License (http://creativecommons.org/licenses/by-nc-nd/4.0/), which permits non-comercial re-use and distribution, provided the original work is properly cited, and is not altered or transformed in any way. 
We are pleased to present nine articles in this special issue, all of which survived the rigorous review process. Each of these articles provides insights into our understanding of a variety of factors that affect entrepreneurial success, depending on the studied context.

We first discuss two core concepts underpinning the focus of this special issue: entrepreneurial dynamics and institutional changes. The mechanisms that are associated with changes made in the entrepreneurial process are then discussed. Finally, we introduce nine articles included in the special issue, categorized in three clusters, namely: hospitality, workforce, and collaborations.

\section{Entrepreneurial Dynamics}

Dynamics is considered to be a key ingredient in order to fully understand entrepreneurship and the entrepreneurial process (Gartner 2003; Aldrich et al. 2002; Lichtenstein et al. 2007). In the context of entrepreneurship, attention has been devoted to nascent entrepreneurs and new venture creation (Reynolds et al. 2004). Lichtenstein et al. (2007) find that new ventures are more likely to come into existence in a situation where nascent entrepreneurs pursue organising activities at a faster rate, and with a lower concentration. The pattern of specific entrepreneurial activities rather than the activities themselves contributes to new venture creation. Following these arguments, it would be logical to expect that adaptation or tension to changes may be the key to the development and growth of new ventures. In other words, adaptive tension could well explain why some firms' founding entrepreneurs are more successful than others. We therefore believe that there is a need to examine the development and growth of new ventures underpinning entrepreneurial dynamics. Entrepreneurial dynamics refers in this special issue to entrepreneurs actively and constantly seeking changes, or making the most appropriate strategic 
choices as a means of overcoming problems and influences that the ventures face, leading to business success.

Previous studies that have attempted to distinguish between successful and unsuccessful startup efforts have found that entrepreneurial dynamics plays an important role in creating a new venture and growing the business (Wright et al. 2007; Colombo and Grilli 2010; Unger et al. 2011). A growing body of literature has acknowledged the importance of entrepreneurs' human capital, motivations, and availability of external finance in creating new ventures, and in determining the subsequent survival and growth (Liu et al. 2010; Gimmon and Levie 2010; Vanaelst et al. 2006; Davidsson and Honig 2003; Shrader and Siegel 2007; Sambasivan et al. 2009). Previous research also suggests that making the best use of expertise and skills, as well as social capital held by the entrepreneurs, is remarkably important in creating a new venture and making a success of the business (Xiao and Ramsden 2016). In other words, making strategic choices that best reflect the availability of resources for the venture and overcome the problems and influences that a venture faces determines the success of businesses (Glancey et al. 1998).

\section{Institutional changes}

North (1990) defines institutions as "any form of constraints that human beings devise to shape human interaction" and broadly divides them into formal (e.g., laws, regulations, rules, contracts) and informal types (e.g., norms, cultures, ethics). Institutional changes emanate from gaps that exist by design or emerge over time between formal institutions and their actual implementation or enforcement, in the absence of exogenous shocks (North 1994). Roland (2004) differentiated 'slow-moving' from 'fast moving' institutions and provided a basis for understanding the interactions among institutions and institutional changes. 'Slow-moving', in 
terms of, institutions, refers to those that change slowly and continuously (i.e., cultures, values, beliefs, and social norms), whilst 'fast-moving' in terms of institutions refers to those that change rapidly and irregularly (i.e., political institutions). 'Slow-moving' institutions that change continuously build up pressure for provoking radical changes. Such interactions between slow-moving and fast-moving institutions suggest that different cultural paths may affect the appropriate choices of fast-moving institutions. 'Fast-moving' institutions in given contexts must in part build on existing slow-moving institutions embedded in cultural and historic pasts.

\section{Entrepreneurial dynamics and institutional changes}

The development of regulatory institutions can influence both business practices and sets of institutional arrangements that govern exchanges in subtle and pervasive ways (Scott 2001). Changes to regulatory institutions may bring about the selection and utilisation of new institutional arrangements (e.g., contracts) more quickly, but influence norms and cultures slowly (Brint and Karabel 1991; DiMaggio 2001). Nevertheless, integration into the institutional environment in which the businesses operate is essential for entrepreneurs to survive and grow their ventures (Peng 2003).

Scholars studying institutional changes find both formal (e.g., contracting and written documents) and informal institutions (e.g., personal network ties) to be particularly useful in explaining firm behaviours (Hitt et al. 2004; Lau et al., 2002; Peng et al. 2009). Scholars also find that informal institutions of personal network ties have a larger influence on the development and growth of firms in economies with weaker and more inefficient regulatory institutions than those in countries with a well-developed institutional framework (Batjargal and Liu 2004; Bruton et al. 2010; Li and Zahra 2012). Entrepreneurs utilising personal network 
ties in order to gather information that is absolutely critical to the venture win contracts and solve disputes in countries with a less developed institutional framework (Bruton and Ahlstrom 2003; Batjargal and Liu 2004; Ahlstrom and Bruton 2006; Le and Nguyen 2009). One of the good examples of this is that personal network ties play a much more important role in making the informal finance market function in transitional economies than in developed countries (Bruton and Ahlstrom 2003; Scheela and Jittrapanun 2012; Batjargal and Liu 2004; Ahlstrom and Bruton 2006; Le and Nguyen 2009; Xiao and North 2012).

The next section introduces the three clusters and nine articles in the special issue, and also highlights the research findings related to the role of the entrepreneurial dynamics that interact with institutional changes in surviving and growing new ventures.

The first three articles included in this special issue reflect the factors that influence the entrepreneurial dynamics in a key international sector such as the hospitality industry. From a global point of view, this is still considered to be an industry that is in constant ascent; indeed, the growth of international tourist excursions has been constant since the 1960s. In 2016 the amount of tourist excursions reached 1,235,000,000 (WTO 2017). This fact is significant in the institutional environment where the empirical works have been developed, Spain being the third most popular country for tourists in the world, after France and the USA. These first articles delve into aspects like growth aspirations or the mechanisms that have made companies achieve competitive advantages within their industrial content. We can see a specific emphasis on the role played by different types of knowledge, such as entrepreneurs' previous experience, entrepreneurs' educational achievements, or the practices used for managing tacit knowledge within the organizations and how they relate to factors within their regional context. The first article of this special issue represents an empirical work, using both hotels and restaurants as a 
sample; the second article analyzes the case of hotels within a growing process; and the third one focuses on a high quality restaurant that has reached its objective level of success.

The first paper by Capelleras, Contín-Pilart, Larraza-Kintana and Martín-Sánchez, the Regional and individual determinants of entrepreneurial growth aspirations, is based on the idea that entrepreneurial growth aspirations are vital to explain the growth of new businesses. This topic is specifically important for entrepreneurial dynamics within the hospitality industry because, as the authors explain in the paper, it is a sector characterized by new ventures that are highly influenced by entrepreneurs' lifestyle objectives. Thus one of the main challenges of this first paper is to combine both individual and environmental effects on growth aspirations. This work presents an analysis of how an entrepreneur's education can act as a moderator for the relationship between population density and their aspirations to grow within their new venture. All the 182 companies included in the study were investigated during the first years of their existence, i.e., within the first 42 months. The authors found that there was a direct positive effect of population density on growth aspiration in the case of the restaurant entrepreneurs, but not in the case of the hotel. However, when they analyzed the case of highly educated entrepreneurs separately, they discovered this positive effect. Moreover, they found that the effect of regional population on growth aspiration is stronger for highly educated entrepreneurs. In their conclusions, the authors assume that the relationship between external conditions and growth aspirations appears to be moderated by the individual capability to interpret the local environment, given the influence of their particular entrepreneurial cognitions. The knowledge generated in this paper helps in the development of strategies to stimulate local entrepreneurial activities, especially in the growth of new and small hospitality firms. 
The second paper, Analysis of knowledge tacitness in the transfer of food and beverage practices: Evidence from new chain hotels, by García-Almeida and Ballesteros-Rodríguez, focuses on the role of knowledge as a valuable resource that can provide a firm with competitive advantages, specifically when a hotel enters into an entrepreneurial dynamic of growth. This dynamic includes transferring the knowledge underlying the key practices within this type of organization. The authors elected to choose, for their empirical analysis, one of the departments - either food or beverages - where the information is not frequently shared through formal channels. In fact, one of the main focuses of this research is the understanding of the processes behind the transfer of the type of knowledge that is more complicated to measure: tacit knowledge. In this paper, the authors describe the level of tacitness of knowledge practice, and the mechanisms applied to transfer it and look for the relationship between the level of tacitness and the transfer success. With this purpose, the authors analyzed data from 93 new chain hotels that were involved in the dynamic of growth.

Based on their empirical analysis, the authors come to relevant conclusions regarding, for example, the practices with a higher and lower level of tacitness. Thus the food planning, production and preparation is the practice with a higher level of tacitness knowledge, whereas the customer services practice is significantly lower. They discover that the main mechanism used in the knowledge transfer is long-term staff from other organizational units. In this respect, the authors find that the more tacit the knowledge, the richer the mechanism used to mobilize the knowledge. This research gives some guidelines about the more effective way of management tacit knowledge when a hotel enters into an entrepreneurial dynamic of growth.

The third paper of this special issue, by Bernardo, Escalante and Arbussà, Analysis of the Catalan haute cuisine success: The role of education and network creation, researches success 
factors, specifically education and the network creation of restaurants that have achieved the classification of high quality. The authors highlight the importance of the relationship of both internal and external factors for the continuous improvement of this type of venture. Therefore the location of the restaurant, and the informal institutions that affect them, influence the possibility of creating more networks and consequently stimulate the creation of new companies within the sector. This research focuses on the case of fifty-four Michelin-starred restaurant chefs, and looks in depth into their specific educational experience and the process during the network creation.

The authors conclude that chefs' education is one of the main mechanisms of knowledge transfer for this type of restaurant, but it became a key starting point for network creation too. The authors conclude that the majority of chefs started their relationships at a professional level and some became personal. As far as the environmental issues are concerned, the authors show how two and three Michelin-starred restaurant chefs act as spillovers for the rest of the sector. This research presents a very interesting analysis about how important education is in order to acquire the basis to understand and enrich fashionable cuisine, and act as a pool of relationships creation.

Moving to the next two papers of the special issue, they focus on one element that is fundamental for any entrepreneurial dynamics, and that is the workforce. The new leaders and decision makers face different challenges regarding their employees' management, affected by factors like the automation of work or the role of employees in the new business models. The next two articles make an interesting review of the literature on two important phenomena employee participation and the presence of women in the workforce - which have continuously increased and have changed the dynamics of human resource management within recent years. 
Although both issues are basic necessities in allowing companies to adapt to the dynamic environment, they are still far from being normal practices. Thus, many organizations continue to face the challenge of designing and applying practices that allow employees to participate actively in the decision making of organizations. The awareness of this favors the motivation and performance of their workers. In addition, despite the increase of women in the workforce, the enormous differences in the proportion of managerial positions held by women continues. It is known that both these aspects are positive for organizations when they are implemented. The fourth article, Employee involvement and participation in SMEs: a synthesis of extant research, by Rohlfer, focuses on the idea that SMEs cannot afford to under-utilize their workforce, and that owners/managers need to encourage ways to engage employees. This research studies employee involvement and participation practice in SMEs. Based on a systematic literature review, the author makes a reflection about the evolution of employee involvement and participation practices, and identifies with key directions for future academic research. The results show, for example, that the most studied involvement practice is representative participation, followed by financial participation. Moreover, she recognises a lack of contextualization of SMEs' reality in the studies analyzed.

The authors conclude that employee involvement and participation dynamics are basically a reflection of the rules, norms and structures of the context in which the companies compete. In this respect, she highlights the importance of understanding how institutional factors, such as the influence of employment laws, can affect the role of employees in the companies and recommend practices like comparative analysis of external factors and internal influences driving employee involvement and participation in SMEs. 
The fifth article, by Ganiyu, Oluwafemi, Ademola, and Olatunji, The Glass Ceiling Conundrum: Illusory beliefs or barriers that impede women's career advancement in the workplace, examines the tendency of the glass ceiling phenomenon that limits women's career development in the workplace. The authors review a series of previous academic works and discover the different perspectives that analyze the glass ceiling barriers issues. From a theoretical point of view they try to understand the conceptual foundations of the glass ceiling through the congruity theory and social role and identity theory. Regarding congruity theory, this work describes how it is common that women are perceived as not desirable for managerial positions when this is not congruent with stereotypes associated with women. Thus, social role theory reinforces the idea that men and women act according to social role (e.g., class) and that between them, gender plays an important role in all societies. Moreover, in the second part of the article they focus on the understanding of restrictions that are still prevalent in the development of women's careers, such as customary gender roles. This paper highlights the relevance of this topic, as the low proportion of women being promoted into management positions, compared to men, is still rife within most companies.

The authors specifically recommend a series of institutional changes to promote strong organizational culture and a more helpful and supportive environment to develop women's leadership skills. Examples of these practices are adaptive workplace policies or workforce diversity strategies. This paper concludes by highlighting the fact that informal institutions do not help women to reach managerial positions. Aspects such as cultural prejudice, religious convictions, family related issues or inadequate opportunities to networks, limit women's progression to the top managerial hierarchy. 
The last four articles of this special issue present the cases of collaboration between private companies, communities and institutions in different sectors like the arts, media and mining industries, and three different institutional contexts, such as English, Peruvian and Spanish. The sixth article of this special issue, Sustainability of a Community-Based Enterprise through shared value. Case: Mallay Communal Company by Muñoz Marticorena, explains the case of how the mining company Buenaventura collaborated with the community of Mallay, in Peru, to create a new venture with the objective of generating shared value within the region. The peasant community of Mallay is located in the Lima region, and the community population is 522 inhabitants. $50 \%$ of the inhabitants were evaluated as being in a state of poverty, and the vast majority of them only have access to basic education. The purpose of the project presented in this case was to organize and manage the economic activities of the community under a business format, through the generation of productive units of communal goods and services. The authors describe how the strategies for the management creation process of the Mallay Community Enterprise came about, and the main social value that has been generated, such as the reduction of social conflicts. One of the necessities detected, which became a key element for the project's development, was the training of community members. These practices allowed the improvement of company income, sanitation and habitat, generating a larger amount of surpluses to be redistributed. The new company has been running for seven years and has employed more than 50 people in the community. This project has redistributed the profits in training, social assistance and reinvestment, improving the quality of community life. This case is an example of how the redefinition of the productivity value chain includes the creation of social value for the different companies that are part of the value chain, and thus for society as a whole. 
The following article Unequal growth and social capital in clothes-making enterprises in Peru: 1980-2015, by Wong, Hernández, Chirinos and Carrasco is developed in the same country as the previous work, Peru. The authors go in depth into the case of four small Peruvian enterprises in the clothing industry, trying to understand the structural and historical conditions that explain their level of performance. The authors found the important role played by the social capital in the prevailing inequality owes. Moreover they analyses how the institutional and structural conditions affects the rhythm of growing within the companies. This work adds an interesting knowledge about how the participation in different type of networks help individuals to develop certain skills.

The eighth article in this special issue, The Arts Council: Entrepreneurial Dynamics and Institutional Changes, by Tattersall, is a reflection of the different factors that affect the entrepreneurial strategic planning of the Arts Council, England. This institution is committed to championing and developing the arts, museums and libraries. It is a custodian of public investment and is charged with getting the maximum value from this, through the promotion of the arts and favoring its accessibility to the public. The analysis of the case of an organization like the Arts Council is relevant for different reasons. This institution represents the English government's mechanism to strategically transform the arts organizations and industries, and to increase the quality of arts activities in the country, but it is also a challenge for their responsibles and managers due to factors like the permanent tension between the expectation of the artistic community and the perceptions of its performance by the government.

This critical and theoretical academic paper delves in depth into the past and more recent statements of policy, with a view to identifying various ideological, structural and procedural determinants that bear upon the decision-making processes. The author develops different open 
questions to make readers reflect; for example, he questions to what extent the Arts Council is prepared to encourage art tendencies that modify existing attitudes and are revolutionary in comparison with the traditional statements and points of view. When there is a finite budget to assign, this example of strategic decision becomes critical. The research highlights the influence made by institutional pressures and debates about the role of a form of 'constructive tension' between that which is deemed necessary to preserve and that which must change and innovate with time.

Finally, the last work in this special issue, on Jesús de Polanco and the Prisa Group, by Cabrera, presents the case of the entrepreneurial career of this Spanish businessman and the creation of the PRISA Group, (Promotora de Informaciones S.A.), which is the leading Spanish multimedia group of its time. It is the greatest communications group in Latin America, with presences in radio, television, print media and publishing. This paper analyses the connections between the company and political institutions during the last years of the Franco dictatorship, and the transition to democracy from a concrete perspective. Those were years characterized by deep institutional transformations, not only from the political point of view but also from the country experiencing important changes in its economy, society and business structures, which affected the entire media communications sector.

This work examines the route of the first years of Jesús Polanco's life, from his years of youth and study, his experiences in Latin America, and his first business activities. The author continuously explains the foundation of the newspaper called El País, the first key project in the future PRISA group, and she assumes that both Jesús Polanco and Cebrian, its first director, are the people responsible for the success of the new business model of this journal, which was founded in 1976. Then the authors make a description of the creation of the PRISA group, the 
changes in its direction and the creation of new business units. All the decisions taken are analyzed based on the political circumstances that the country was experiencing in each moment. The author concludes by reinforcing the importance of Jesus Polanco's technological consciousness, and how it has helped PRISA's evolution and allowed it to continue competing and leading in a hard and changing industry.

\section{References}

Ahlstrom, David, and Garry Bruton. 2006. "Venture capital in Emerging Economics: Networks and Institutional changes.” Entrepreneurship Theory and Practice 30 (1): 299-320.

Aldrich, Howard E., Nancy M. Carter, and Martin Ruef. 2002. "With very little help from their friends: gender and relational composition of nascent entrepreneurs' startup teams." Paper presented at the Babson College Kauffman Foundation Entrepreneurship Research Conference, Boulder, CO, June.

Batjargal, Bat, and Mannie Liu. 2004. "Entrepreneurs' access to private equity in China: the role of social capital." Organisation Science 15 (2): 159-172.

Brint, Steven, and Jerome Karabel. 1991. "Institutional origins and transformations: The case of American community colleges." In The New Institutionalism in Organisational Analysis, edited by W.W. Powell, and P.J. DiMaggio, 337-60. Chicago: University of Chicago Press.

Bruton, Garry, and David Ahlstrom. 2003. "An institutional view of China's venture capital industry: explaining the differences between China and the West." Journal of Business Venturing 18:233259.

Bruton, Garry, David Ahlstrom, and Han-Lin Li. 2010. "Institutional theory and entrepreneurship: where are we now and where do we need to move in the future?" Entrepreneurship Theory and Practice 34 (3): 421-440.

Colombo, Massimo G., and Luca Grilli. 2010. "On growth drivers of high-tech start-ups: exploring the role offounders' human capital and venture capital." Journal of Business Venturing 26 (6): 610626.

Davidsson, Per, and Benson Honig. 2003. "The role of social and human capital among nascent entrepreneurs." Journal of Business Venturing 18 (3): 301-331.

DiMaggio, Paul. 2001. The twenty-first century firm: changing economic organisation in international perspective. Princeton: Princeton University Press. 
Gartner, William B., Nancy M. Carter, and Gerald E. Hills. 2003. "The language of opportunity.” In New Movements in Entrepreneurship, edited by Chris Steyaert, and Daniel Hjorth, 103-124. London: Edward Elgar.

Gimmon, Eli, and Jonathan Levie. 2010. "Founder's human capital, external investment, and the survival of new high-technology ventures.” Research Policy 39 (9): 1214-1226.

Hitt, Michael A., David Ahlstrom, M. Tina Dacin, Edward Levitas, and Lilia Svobodina. 2004. "The institutional effects on strategic alliance partner selection in transition economies: China versus Russia." Organisation Science 15 (2): 173-85.

Lau, Chung-Ming, David K. Tse, and Nan Zhou. 2002. "Institutional forces and organizational culture in China: Effects on change schemas, firm commitment and job satisfaction." Journal of International Business Studies 33 (3): 533-550.

Le, Ngoc T.B., and Thang V. Nguyen. 2009. "The impact of networking on bank financing: the case of small and medium-sized enterprises in Vietnam." Entrepreneurship Theory and Practice 33 (4): 867-887.

Li, Yong, and Shaker A. Zahra. 2012. "Formal institutions, culture, and venture capital activity: a crosscountry analysis.” Journal of Business Venturing 27 (1): 95-111.

Lichtenstein Benyamin.B., Nancy M. Carter, Kevin Dooley, and William B. Gartner. 2007. "Complexity dynamics of nascent entrepreneurship." Journal of Business Venturing 22 (2): 236-261.

Liu, Xiaohui, Mike Wright, Igor Filatotchev, Ou Dai, and Jiangyong Lu. 2010. "Human mobility and international knowledge spillovers: evidence from high-tech small and medium enterprises in an emerging market." Strategic Entrepreneurship Journal 4 (4): 340-355.

Glancey, Keith, Malcolm Greig, and Malcolm Pettigrew. 1998. "Entrepreneurial dynamics in small business service firms." International Journal of Entrepreneurial Behavior \& Research 4:249268.

North, Douglass C. 1990. Institutions, institutional change and economic performance. Cambridge: Cambridge University Press.

North, Douglass C. 1994. "Economic performance through time." The American Economic Review 84 (3): 359-368.

Peng, Mike W. 2003. "Institutional transitions and strategic choices." Academy of Management Review 28 (2): 275-96.

Peng, Mike, Sunny L. Sun, Brian Pinkham, and Hao Chen. 2009. "The institution-based view as a third leg for a strategy tripod." Academy of Management Perspectives 23 (3): 63-91. 
Reynolds, Paul D., Nancy M. Carter, William B. Gartner, and Patricia G. Greene. 2004. "The prevalence of nascent entrepreneurs in the United States: evidence from the panel study of entrepreneurial dynamics." Small Business Economics 23:263-284.

Roland, Gerard. 2004. "Understanding institutional changes: fast-moving and slow-moving institutions." Studies in Comparative International Development 38:109-131.

Sambasivan, Murali, Mohani Abdul, and Yuzliani Yusop. 2009. "Impact of personal qualities and management skills of entrepreneurs on venture performance in Malaysia: opportunity recognition skills as a meditating factor." Technovation 29 (11): 798-805.

Scheela, William, and Thawatchai Jittrapanun. 2012. "Do institutions matter for business angel investing in emerging Asian markets?" Venture Capital 14 (4): 289-308.

Scott, W. Richard. 2001. Institutions and organizations. Thousante Oakes: Sage.

Shrader, Rod, and Donald S. Siegel. 2007. "Assessing the relationship between human capital and firm performance: evidence from technology-based new ventures." Entrepreneurship theory and Practice 31 (6): 893-908.

Unger, Jens M., Andreas Rauch, Michael Frese, and Nina Rosenbusch. 2011. "Human capital and entrepreneurial success: a meta-analytical review.” Journal of Business Venturing 26 (3): 341358.

Vanaelst, Iris, Bart Clarysse, Mike Wright, Andy Lockett, Nathalie Moray, and Rosette S'Jegers. 2006. "Entrepreneurial team development in academic spin-outs: an examination of team heterogeneity." Entrepreneurship Theory and Practice 30 (2): 249-271.

Wright, Mike, Keith M. Hmieleski, Donald Siegel, and Michael Ensley. 2007. "The role of human capital in technological entrepreneurship." Entrepreneurship Theory and Practice 31 (6): 791806.

World Tourism $\quad$ Organization. 2017. Annual Report 2017. http://cf.cdn.unwto.org/sites/all/files/pdf/annual_report_2016_web_0.pdf

Xiao, Li, and David North. 2012. "Institutional transition and the financing of high-tech SMEs in China: a longitudinal perspective." Venture Capital 14 (4): 242-269.

Xiao, Li, and Mark Ramsden. 2016. "Founder expertise, strategic choices, formation and survival of high-tech SMEs in China: a resource-substitution approach." Journal of Small Business Management 54:892-911.

This is an Open Access article distributed under the terms of the Creative Commons Attribution-Non-Commercial-No Derivatives License (http://creativecommons.org/licenses/by-nc-nd/4.0/), which permits non-comercial re-use and distribution, provided the original work is properly cited, and is not altered or transformed in any way. 